\title{
Two year follow up of pulmonary function values among welders in New Zealand
}

Riitta Erkinjuntti-Pekkanen, Tania Slater, Soo Cheng, David Fishwick, Lisa Bradshaw, Mona Kimbell-Dunn, Liz Dronfield, Neil Pearce

\begin{abstract}
Objectives-To examine whether welding is a risk factor for an accelerated decline in pulmonary function.

Methods-2 Year follow up of pulmonary function and respiratory symptoms among 54 welders and 38 non-welders in eight New Zealand welding sites.

Results-There were no significant differences in age, height, smoking habits, ethnicity, or total time in industrial work between welders and non-welders. No overall differences were noted in the changes of pulmonary function variables between the two study groups. However, when the comparison was restricted to smokers, welders had a significantly greater $(p=0.02)$ annual decline $(88.8 \mathrm{ml})$ in FEV $_{1}$ than non-welders, who had a slight non-significant annual increase $(34.2 \mathrm{ml})$. Also, welders without respiratory protection or local exhaust ventilation while welding had a greater annual decline both in forced vital capacity (FVC) and forced expiratory volume in one second $\left(F_{E V}\right)$ than welders with protection ( $p=0.001$ and 0.04 , respectively). Among welders a significant association was found between the acute across shift change and the annual decline in $\mathrm{FEV}_{1}$. Chronic bronchitis was more common among welders (24\%) than non-welders $(5 \%)$. Only one welder (2\%) but eight nonwelders $(21 \%)$ reported having asthma.

Conclusions-Welders who smoked and welders working without local exhaust ventilation or respiratory protection have an increased risk of accelerated decline in $\mathbf{F E V}_{1}$.

(Occup Environ Med 1999;56:328-333)
\end{abstract}

Keywords: pulmonary function; welding fume; follow up study

Finland

R Erkinjuntti-Pekkanen

Sheffield Occupational and Environmental Lung Injury Centre, Royal Hallamshire Hospital, Glossop Road, Sheffield, UK D Fishwick

Correspondence to: Dr Riitta

Erkinjuntti-Pekkanen,

Department of Pulmonary

Diseases, Kuopio University

Hospital, PO Box 1777,

70211, Kuopio, Finland. Fax 0035817172685 .

Accepted 18 December 1998

Exposure to welding fumes is known to be a risk factor for respiratory disorders. Welding fumes may cause acute respiratory effects including airway irritation, acute bronchitis, metal fume fever, and, less commonly, hypersensitivity pneumonitis or occupational asthma. ${ }^{1}$ Welders are also known to have a higher risk for chronic respiratory disorderssuch as pneumoconiosis, ${ }^{1}$ chronic bronchitis, ${ }^{1}$ and lung cancer. ${ }^{2}$

Several studies have shown a small acute decline in lung function during welding work, ${ }^{3-5}$ although this effect has not been noted in all studies. ${ }^{67}$ The long term significance of this acute decline is still unclear, although it is possible that repeated acute declines could result in the development of chronic respiratory impairment. Knowledge of the chronic effect of welding fumes on lung function is mainly based on cross sectional studies of current workers. ${ }^{18-10}$ Only a few longitudinal studies have been published, ${ }^{11-13}$ with conflicting results. Chinn et $a l^{11}$ found an irreversible effect of welding on forced expiratory volume in one second $\left(\mathrm{FEV}_{1}\right)$ and forced vital capacity (FVC) in a 7 year follow up of welders and caulker/burners, and they also noted an interaction between the effects of smoking and welding. Beckett et $a l^{13}$ did not find any effect of welding on the annual decline of lung function in a 3 year follow up.

In 1996 a cross sectional survey was conducted in eight different New Zealand engineering sites and found that an acute decrease in $\mathrm{FEV}_{1}$ relative to work was more prevalent among welders than among non-welders. ${ }^{14}$ In that study welders had a mean $2.8 \%$ fall from baseline $\mathrm{FEV}_{1}$ after 15 minutes of work compared with a $1.0 \%$ increase in non-welders. The purpose of the present survey was to study the same workers 2 years after the previous study and to examine whether welders also had an accelerated chronic decline in lung function.

Subjects and methods

A 2 year follow up visit was performed at the same eight New Zealand engineering sites studied in the first survey in $1996 .{ }^{14}$ All sites were known to regularly involve welding as part of their industrial process. Most of the welders studied worked with mild steel or mild steel and stainless steel as a base metal, with either gas tungsten arc welding (TIG) or gas metal arc welding (MIG) techniques.

\section{QUESTIONNAIRE}

As in the previous study, the questionnaire included demographic data, current smoking habits, questions about work related respiratory symptoms, and selected questions from the European Community Respiratory Health Survey. ${ }^{15}$ Reports of current or recent cough, phlegm, wheeze, chest tightness, and shortness of breath were recorded, along with whether these symptoms were related to work (defined as a symptom reported to be worse at work or improving on rest days or holidays).

Smoking was divided into two categories: smokers included all current smokers during study 1 (it includes four smokers who stopped smoking between the two studies), and non- 
smokers included both never smokers and long term ex-smokers. Chronic bronchitis was defined as regular phlegm production at any time during the day or night for $\geqslant 3$ months of the year and for $\geqslant 2$ years.

\section{CURRENT WELDING EXPOSURE}

The current job type and the duration of employment were recorded both in the first and the second survey, but the basic definitions were based on the welding status at the time of study 1 . A worker was classified as a welder if he had been an active welder (welding $\geqslant 5 \%$ of the working day) in study 1 and had continued in that job between the two surveys (this includes seven welders who stopped welding between study 1 and study 2 with a mean stopping date of 4 months before study 2). Non-welders were defined as all workers who had never worked as welders and workers who were ex-welders at the time of the study 1 or at that time did only minimal welding ( $\geqslant 5 \%$ of the working day) and had not been active welders between the two surveys.

\section{PREVIOUS WELDING EXPOSURE}

Similarly, welding history was recorded at both surveys but the basic definitions were based on the welding history at the time of study 1 . All workers were asked to describe their previous lifetime exposure in terms of sequential periods spent in differing jobs, and the associated proportion of the day spent welding in each of these posts. The effective exposure in years (per job) was calculated as the product of these two variables, and the cumulative measure (years) was calculated by summing all the individual exposures for each job. This estimate is subsequently referred to as the total exposure index. ${ }^{14}$

PULMONARY FUNCTION

All workers in the study were asked to perform pulmonary function tests with one of the two calibrated portable spirometers (Alpha Spirometer, Vitalograph) used in the first survey. Otherwise the protocol was the same as in study $1 .{ }^{14}$ Pulmonary function measurements, carried out according to the guidelines set by Quanjier et $a l,{ }^{16}$ were taken before the shift, 15 minutes after the start of welding work (or at a corresponding time for workers not welding) and again 7 hours into the workshift. All preshift values were recorded before any exposure to welding fumes on the study day and was at least 14 hours since any previous welding work. Forced expiratory volume in one second (1), forced vital capacity (l) and forced midexpiratory flow $\left(\mathrm{FEF}_{25-75} 1 / \mathrm{s}\right)$ were measured, with the best value of three forced expiratory manoeuvres in the standing position.

All variables were also converted into the percentage predicted value for each person with the equations integral in the spirometer, ${ }^{16}$ including adjustment for ethnicity (Polynesian and non-Polynesian).

The two spirometers used in the study 1 differed from each other with a mean difference of $4 \%$ in the $\mathrm{FEV}_{1}$ measurements after adjust- ment for age, sex, and height. Because only one of these spirometers was used in the second study, the analysis was adjusted for which spirometer was used in the first study. Thus, for the 23 welders and 21 non-welders who used one spirometer (A) in the first study but the other spirometer (B) in the second study, their pulmonary function measurements for study 1 were adjusted to account for the difference in mean $\mathrm{FEV}_{1}$ measurements between the two spirometers (controlling for age, sex, height, and ethnicity). The other 20 welders and 14 non-welders used the same spirometer (B) in both studies.

\section{DATA ANALYSIS}

The statistical analysis system (SAS) ${ }^{17}$ was used for all regression analyses. The mean pulmonary function values were adjusted for age and height as a continuous variable, spirometer, smoking habit in three groups (current, ex-smoker and non-smokers), and ethnicity in two groups (European and non-Europeanwhich includes both Maori and other Polynesians) in an analysis of covariance (ANCOVA). This calculates what the mean values would have been if the age, height, smoking, ethnicity, and spirometer distributions were the same in the groups being compared-for example, welders and non-welders.

Continuous variables were compared between groups - for example, welders and nonwelders-by estimating the mean (SEM) and the associated unpaired $t$ test. Categorical variables were compared between groups with the standard $\chi^{2}$ test.

The annual changes in pulmonary function values were calculated from the preshift values for each person as the difference between their pulmonary function values in study 1 and study 2 divided by the time between the two measurements (about 2 years) with the adjusted mean values. Linear regression was used to measure the change in annual decline in pulmonary function values $(\mathrm{ml})$ for a $1 \%$ acute decline in $\mathrm{FEV}_{1}$ measured across the shift in study 1 .

All workers in this study gave written informed consent to take part and the study was approved by the Wellington ethics committee.

\section{Results}

Of the 137 workers studied in 1996, 96 (70\%) participated in this second survey, of whom two were retired, two were on sick leave, one was unemployed, and six had changed job; these 11 workers were visited at home or at their new place of work. Only four women participated in the study; they were all non-welders and were excluded from the analysis. Forty one workers could not be included in the second study (mostly because they could not be contacted), however, those 21 welders and 20 non-welders who did not participate did not differ from those who participated in terms of mean age or pulmonary function values. The response rates were $54 / 61(89 \%)$ in male welders and $38 / 70$ $(54 \%)$ in male non-welders. 
Table 1 Demographic characteristics and welding and smoking history of the welders and non-welders

\begin{tabular}{|c|c|c|c|c|c|}
\hline & \multicolumn{2}{|c|}{ Welders $(n=54)$} & \multicolumn{2}{|c|}{ Non-welders $(n=38)$} & \multirow[b]{2}{*}{$p$ Value } \\
\hline & Mean & $S D$ & Mean & $S D$ & \\
\hline Age (y) & 40.1 & 11.6 & 41.4 & 13.6 & 0.6 \\
\hline Height $(\mathrm{cm})$ & 176.5 & 7.8 & 177.8 & 8.0 & 0.5 \\
\hline Total exposure index & 7.9 & 6.8 & 0.9 & 2.1 & 0.0001 \\
\hline Total time in industry & $\begin{array}{l}17.4 \\
n\end{array}$ & $\begin{array}{l}10.5 \\
\%\end{array}$ & $\begin{array}{l}15.5 \\
n\end{array}$ & $\begin{array}{l}14.4 \\
\%\end{array}$ & 0.5 \\
\hline Current smokers & 24 & 44.4 & 13 & 34.2 & 0.3 \\
\hline Ex-smokers & 10 & 18.5 & 10 & 26.3 & 0.4 \\
\hline Non-smokers & 20 & 37.0 & 15 & 39.5 & 0.8 \\
\hline European & 36 & 66.7 & 31 & 81.6 & 0.1 \\
\hline
\end{tabular}

All data based on study 1 , except age in study 2 .

Table 2 Asthma, atopy, chronic bronchitis, work related and general respiratory symptoms in welders and non-welders at the time of study 2

\begin{tabular}{|c|c|c|c|c|c|}
\hline & \multicolumn{2}{|c|}{ Welders $(n=54)$} & \multicolumn{2}{|c|}{ Non-welders $(n=38)$} & \multirow[b]{2}{*}{$p$ Value } \\
\hline & $n$ & $\%$ & $n$ & $\%$ & \\
\hline Asthma & 1 & 1.9 & 8 & 21.1 & 0.002 \\
\hline Nasal allergies & 17 & 31.5 & 14 & 36.8 & 0.6 \\
\hline Skin allergies & 13 & 24.1 & 10 & 26.3 & 0.8 \\
\hline Chronic bronchitis & 13 & 24.1 & 2 & 5.3 & 0.02 \\
\hline \multicolumn{6}{|l|}{ Work related symptoms: } \\
\hline Cough & 7 & 13.0 & 4 & 10.5 & 0.7 \\
\hline Phlegm & 12 & 22.2 & 5 & 13.2 & 0.3 \\
\hline Wheezing & 6 & 11.1 & 2 & 5.3 & 0.3 \\
\hline Shortness of breath & 1 & 1.9 & 2 & 5.3 & 0.4 \\
\hline Chest tightness & 7 & 13.0 & 5 & 13.2 & 1.0 \\
\hline Any work related symptom & 16 & 29.6 & 9 & 23.7 & 0.5 \\
\hline \multicolumn{6}{|l|}{ Respiratory symptoms: } \\
\hline Persistent cough & 9 & 16.7 & 7 & 18.4 & 0.8 \\
\hline Any chest tightness & 17 & 31.5 & 13 & 34.2 & 0.8 \\
\hline Chest tightness just with colds & 4 & 7.4 & 1 & 2.6 & 0.3 \\
\hline Wheeze or whistle in past 12 months & 18 & 33.3 & 15 & 39.5 & 0.5 \\
\hline Wheezing only with colds & 11 & 20.4 & 6 & 15.8 & 0.6 \\
\hline Shortness of breath grade 1 & 6 & 11.1 & 7 & 18.4 & 0.7 \\
\hline
\end{tabular}

Table 3 Adjusted $^{\star}$ pulmonary function values in study 1 and study 2, and the annual change among welders and non-welders

\begin{tabular}{|c|c|c|c|c|}
\hline & \multicolumn{2}{|l|}{ Welders } & \multicolumn{2}{|c|}{ Non-welders } \\
\hline & Mean * & $S E$ & Mean* & $S E$ \\
\hline Study 1 & $\mathrm{n}=48$ & & $\mathrm{n}=37$ & \\
\hline FVC (1) & 4.85 & 0.11 & 4.94 & 0.13 \\
\hline $\mathrm{FEV}_{1}(\mathrm{l})$ & 3.83 & 0.08 & 3.85 & 0.09 \\
\hline $\mathrm{FEF}_{25-75}(\mathrm{l} / \mathrm{s})$ & 3.46 & 0.15 & 3.36 & 0.18 \\
\hline Study 2 & $\mathrm{n}=43$ & & $\mathrm{n}=35$ & \\
\hline FVC(1) & 4.75 & 0.11 & 4.83 & 0.12 \\
\hline $\mathrm{FEV}_{1}(1)$ & 3.78 & 0.08 & 3.81 & 0.09 \\
\hline $\mathrm{FEF}_{25-75}(1 / \mathrm{s})$ & 3.59 & 0.18 & 3.71 & 0.21 \\
\hline Annual change & $\mathrm{n}=43$ & & $\mathrm{n}=35$ & \\
\hline $\mathrm{FVC}(\mathrm{ml})$ & -64.6 & 38.9 & -65.0 & 45.0 \\
\hline $\mathrm{FEV}_{1}(\mathrm{ml})$ & -26.4 & 21.3 & -33.1 & 24.6 \\
\hline $\mathrm{FEF}_{25-75}(\mathrm{ml} / \mathrm{s})$ & 78.0 & 62.1 & 162.9 & 71.8 \\
\hline & Mean & $95 \% C I$ & & $p$ Value \\
\hline \multicolumn{5}{|c|}{ Annual change welders $v$ non-welders: } \\
\hline $\mathrm{FVC}(\mathrm{ml})$ & 0.4 & -107.4 to 108.1 & & 0.99 \\
\hline $\mathrm{FEV}_{1}(\mathrm{ml})$ & 6.7 & -52.3 to 65.7 & & 0.82 \\
\hline $\mathrm{FEF}_{25-75}(\mathrm{ml} / \mathrm{s})$ & -84.8 & -256.8 to 87.2 & & 0.33 \\
\hline
\end{tabular}

^ Adjusted for age, height, smoking (current smokers, ex-smokers, and non-smokers), spirometer used, and ethnicity (European and non-European).

Table 1 shows the demographic details and smoking status of the study groups. The 54 welders did not differ significantly from the 38 non-welders in terms of age, height, total time in the industry, smoking habits, and ethnicity. The mean total exposure index was 7.9 years among welders and 0.9 years among nonwelders (some of these were longtime exwelders or had done minimal welding).

Table 2 shows the prevalence of asthma and respiratory symptoms at the time of study 2 in welders and non-welders. Only one welder but eight non-welders reported having asthma.
Chronic bronchitis was much more common among welders (24\%) than among nonwelders $(5 \%)$. Four of the $20(20 \%)$ welders who had never smoked had chronic bronchitis compared with none of the 15 non-welders who had never smoked. Of the work related symptoms only phlegm production and wheezing were more often reported by welders $(22 \%$ and $11 \%$ ) than non-welders (13\% and $5 \%$ ), but these differences were not significant. Many of the general respiratory symptoms were more common among non-welders, presumably because of the eight asthmatic workers in that group.

Spirometry values of 78 workers were included to the analysis; two others declined to be tested, six were excluded as they had been welding during the preceding 14 hours (before baseline was measured at the start of the working day), four measurements did not reach the reproducibility criteria and from three workers we obtained only the questionnaire data as they were only interviewed by telephone. The response rates for spirometry were 43/61 $(71 \%)$ in male welders and $35 / 70(50 \%)$ in male non-welders.

The mean (SD) percentage of the predicted pulmonary function values did not differ significantly between the welders and nonwelders. These were: FVC 102.8 (13.5) in welders and 105.0 (15.8) in non-welders; $\mathrm{FEV}_{1}$ 98.4 (13.7) and 98.7 (14.3); and $\mathrm{FEF}_{25-75} 80.2$ (23.6) and 83.0 (26.7).

The annual decline in pulmonary function did not differ significantly between welders and non-welders (table 3). However, when the analysis was restricted to smokers, welders had a significantly $(\mathrm{p}=0.02)$ greater annual decline in $\mathrm{FEV}_{1}$ than non-welders (table 4); the difference in the annual decline in $\mathrm{FEF}_{25-75}$ also tended to be greater among welders who smoked than non-welders who smoked, but this difference was not significant $(p=0.08)$. The findings were similar after adjusting for pack-years of smoking. Among non-smokers the result was the reverse; non-welders had a steeper annual decline in $\mathrm{FEV}_{1}$ than welders $(p=0.05)$. The high number of asthmatic workers among the non-smoking non-welders did not explain this pattern as excluding them from the analysis did not significantly change the findings; there were also some $(n=3)$ ex-smokers and ex-welders in the group of non-smoking non-welders but excluding them did not change the findings.

At the time of the first survey, 27 (50\%) of the 54 welders had used either a personal respirator or local exhaust ventilation, or both while welding: 20 used a mask, four used an air purifier, and 13 had a local exhaust ventilation. Welders without any personal protection used while welding had a significantly steeper annual decline in $\mathrm{FEV}_{1}$ and FVC than welders with protection (table 5). As the decline was noted both in FVC and $\mathrm{FEV}_{1}$, it was therefore partly related to volume. Welders who smoked and worked without protection had the steepest $(144 \mathrm{ml})$ decline in $\mathrm{FEV}_{1}$ whereas welders with protection who did not smoke had a slight 
Table 4 Adjusted ${ }^{\star}$ pulmonary function values in study 1 and study 2, and the mean annual change by smoking status in welders and non-welders

\begin{tabular}{|c|c|c|c|c|c|c|c|c|}
\hline & \multicolumn{4}{|l|}{ Smokers } & \multicolumn{4}{|c|}{ Non-smokers } \\
\hline & \multicolumn{2}{|l|}{ Welders } & \multicolumn{2}{|c|}{ Non-welders } & \multicolumn{2}{|l|}{ Welders } & \multicolumn{2}{|c|}{ Non-welders } \\
\hline & Mean * & $S E$ & Mean* & $S E$ & Mean* & $S E$ & Mean * & $S E$ \\
\hline \multicolumn{9}{|l|}{ Study 1: } \\
\hline $\mathrm{n}$ & 20 & & 12 & & 28 & & 25 & \\
\hline FVC (1) & 4.79 & 0.18 & 4.84 & 0.23 & 4.87 & 0.14 & 5.00 & 0.17 \\
\hline $\mathrm{FEV}_{1}(\mathrm{l})$ & 3.77 & 0.14 & 3.77 & 0.18 & 3.83 & 0.09 & 3.85 & 0.11 \\
\hline $\mathrm{FEF}_{25-75}(1 / \mathrm{s})$ & 3.51 & 0.26 & 3.47 & 0.34 & 3.43 & 0.19 & 3.29 & 0.23 \\
\hline \multicolumn{9}{|l|}{ Study 2 : } \\
\hline $\mathrm{n}$ & 17 & & 11 & & 26 & & 24 & \\
\hline $\mathrm{FVC}(\mathrm{l})$ & 4.59 & 0.18 & 4.73 & 0.22 & 4.74 & 0.15 & 4.83 & 0.17 \\
\hline $\mathrm{FEV}_{1}(\mathrm{l})$ & 3.66 & 0.15 & 3.87 & 0.18 & 3.79 & 0.09 & 3.68 & 0.11 \\
\hline $\mathrm{FEF}_{25-75}(1 / \mathrm{s})$ & 3.46 & 0.34 & 4.27 & 0.41 & 3.70 & 0.20 & 3.33 & 0.24 \\
\hline \multicolumn{9}{|l|}{ Annual change: } \\
\hline $\mathrm{n}$ & 17 & & 11 & & 26 & & 24 & \\
\hline $\mathrm{FVC}(\mathrm{ml})$ & -166.7 & 84.0 & -28.8 & 103.2 & -49.0 & 40.6 & -96.1 & 48.5 \\
\hline $\mathrm{FEV}_{1}(\mathrm{ml})$ & -88.8 & 29.8 & 34.2 & 36.6 & 4.3 & 28.1 & -75.8 & 33.6 \\
\hline \multirow[t]{2}{*}{$\mathrm{FEF}_{25-75}(\mathrm{ml} / \mathrm{s})$} & -36.0 & 118.2 & 315.9 & 145.1 & 178.3 & 69.1 & 60.2 & 82.6 \\
\hline & Mean & $95 \% C I$ & & $p$ Value & Mean & $95 \% C I$ & & $p$ Value \\
\hline \multicolumn{9}{|c|}{$\begin{array}{l}\text { Annual change welders } v \\
\text { non-welders: }\end{array}$} \\
\hline $\mathrm{FVC}(\mathrm{ml})$ & -137.9 & -423.4 & & 0.33 & 47.1 & -67.9 to 162.1 & & 0.41 \\
\hline $\mathrm{FEV}_{1}(\mathrm{ml})$ & -123.0 & -224.2 & & 0.02 & 80.2 & 0.5 to 159.8 & & 0.05 \\
\hline $\mathrm{FEF}_{25-75}(\mathrm{ml} / \mathrm{s})$ & -351.9 & -753.4 & & 0.08 & 118.1 & -77.8 to 314.0 & & 0.23 \\
\hline
\end{tabular}

^Adjusted for age, height, smoking habit (current, ex-and non-smokers), spirometer, ethnicity (European and non-European).

$\mathrm{SE}=$ standard error.

annual increase $(12 \mathrm{ml})$ in $\mathrm{FEV}_{1}$ (not shown in tables).

Welders who showed the most acute decline in $\mathrm{FEV}_{1}$ across the shift in study 1 also had a greatest annual decline in $\mathrm{FEV}_{1}$ but not in FVC or $\mathrm{FEF}_{25-75}$ (table 6).

Table 5 Pulmonary function values in study 1 and study 2, and the annual change separately in welders with and without respiratory protection or local exhaust ventilation in use while welding

\begin{tabular}{|c|c|c|c|c|}
\hline & \multicolumn{2}{|c|}{ Protection } & \multicolumn{2}{|c|}{ No protection } \\
\hline & Mean * & $S E$ & Mean* & $S E$ \\
\hline \multicolumn{5}{|l|}{ Study 1: } \\
\hline $\mathrm{n}$ & 27 & & 21 & \\
\hline FVC (1) & 4.61 & 0.14 & 5.19 & 0.16 \\
\hline $\mathrm{FEV}_{1}(\mathrm{l})$ & 3.74 & 0.10 & 3.95 & 0.11 \\
\hline $\mathrm{FEF}_{2577}(1 / \mathrm{s})$ & 3.51 & 0.20 & 3.39 & 0.23 \\
\hline \multicolumn{5}{|l|}{ Study 2 : } \\
\hline $\mathrm{n}$ & 26 & & 17 & \\
\hline FVC(1) & 4.68 & 0.13 & 4.85 & 0.17 \\
\hline $\mathrm{FEV}_{1}(1)$ & 3.78 & 0.10 & 3.78 & 0.12 \\
\hline $\mathrm{FEF}_{25-75}(1 / \mathrm{s})$ & 3.70 & 0.22 & 3.41 & 0.28 \\
\hline \multicolumn{5}{|l|}{ Annual change: } \\
\hline $\mathrm{n}$ & 26 & & 17 & \\
\hline $\mathrm{FVC}(\mathrm{ml})$ & 26.6 & 45.2 & -215.0 & 57.4 \\
\hline $\mathrm{FEV}_{1}(\mathrm{ml})$ & 6.6 & 25.9 & -80.7 & 32.8 \\
\hline $\mathrm{FEF}_{25-75}(\mathrm{ml} / \mathrm{s})$ & 65.7 & 77.9 & 98.3 & 98.8 \\
\hline & Mean & $95 \% C I$ & & $p$ Value \\
\hline \multicolumn{5}{|c|}{ Annual change welders with $v$ without protection: } \\
\hline $\mathrm{FVC}(\mathrm{ml})$ & 241.6 & 99.1 & 384.0 & 0.001 \\
\hline $\mathrm{FEV}_{1}(\mathrm{ml})$ & 87.3 & 5.7 & 168.8 & 0.04 \\
\hline $\mathrm{FEF}_{25-75}(\mathrm{ml} / \mathrm{s})$ & -32.6 & -278.0 & 212.8 & 0.79 \\
\hline
\end{tabular}

${ }^{\star}$ Adjusted for age, height, smoking habit (current smokers, ex-smokers, and non-smokers), spirometer, ethnicity (European and non-European).

Table 6 Change in annual decline in pulmonary function values $(\mathrm{ml}) / 1 \%$ acute decline in FEV $V_{1}$ across the shift in study 1

\begin{tabular}{llll}
\hline & $F V C$ & $F E V_{1}$ & FEF \\
& & & \\
\hline Welders & \\
n & 42 & 42 & 42 \\
Annual decline $/ 1 \%$ acute decline in study $1^{\star}$ & -0.9 & 4.4 & 3.6 \\
SE & 3.5 & 1.8 & 4.1 \\
p Value & 0.8 & 0.02 & 0.4 \\
Non-welders: & & & \\
n & 34 & 34 & 34 \\
Annual decline per $1 \%$ acute decline in study $1^{\star}$ & 11.7 & 3.1 & -5.0 \\
SE & 5.4 & 2.9 & 10.9 \\
p Value & 0.04 & 0.3 & 0.7
\end{tabular}

* Adjusted for age, height, smoking (current smokers, ex-smokers and non-smokers), spirometer, ethnicity (European and non-European).

\section{Discussion}

In this 2 year follow up no significant overall differences were noted in the annual changes in pulmonary function variables between welders and non-welders. However, when the comparison was restricted to smokers, welders had a significantly steeper annual decline in $\mathrm{FEV}_{1}$ than non-welders. Chronic bronchitis was more common among welders (24\%) than non-welders (5\%), and especially notable was the difference in the presence of chronic bronchitis in lifetime non-smokers: $20 \%$ in welders and $0 \%$ in non-welders. Only one welder $(2 \%)$ but eight non-welders $(21 \%)$ reported having asthma.

Our findings should be treated with caution because of the lack of an overall difference between welders and non-welders in annual changes in pulmonary function variables, and because of the number of comparisons that were made. Nevertheless, our findings in smokers are consistent for those of several cross sectional studies ${ }^{81018}$ and of one longitudinal study. ${ }^{11}$ Cotes et $a l^{10}$ found that $\mathrm{FEV}_{1}$ was reduced relative to the average welding exposure among current and ex-smokers but not among non-smokers. Cross sectional studies by Hunnicutt et $a l^{8}$ and Özdemir et $a l^{18}$ found significantly impaired pulmonary function among welders who smoked compared with controls who smoked but not among non-smokers. In a 7 year follow up of 488 shipyard workers by Chinn et $a l^{11}$ welders who smoked had nearly twice the annual decline in $\mathrm{FEV}_{1}(50 \mathrm{ml})$ than welders who did not smoke $(37 \mathrm{ml})$, and three times more than controls who did not smoke (16 ml).

Thus our findings, together with those from previous studies, strongly suggest that there is a synergistic relation between the effects of smoking and welding exposure, causing airway narrowing of both large and small airways and chronic bronchitis. The mechanism of this interaction is not exactly known, but the basic 
pulmonary responses to both smoking and certain occupational exposures-for example, inorganic dust-are similar, both involving polymorphonuclear recruitment and alveolar macrophage activation. Thus, it is plausible that there could be a synergistic effect of smoking and exposures to welding fume. ${ }^{19}$

In our study, half of the welders did not have available or use any respiratory protection, and only a quarter had local exhaust ventilation, which is recommended. Welders without any protection while welding had a greater annual decline both in FVC and $\mathrm{FEV}_{1}$ than welders with protection. The steepest annual decline in $\mathrm{FEV}_{1}$ was found in welders who smoked and did not have any respiratory protection.

The relation between respiratory protection and pulmonary function values among welders has rarely been reported in previous studies. In the study by Beckett et $a l^{13}$ all welders had proper preventive measures and they could not find any evidence for chronic irreversible effects on lung function. Similarly, all workers studied by Chinn et $a l^{12}$ in their second follow up had local exhaust ventilation. They classified welders by regular (100\% of the time) and non-regular use of exhaust ventilation, and found that the annual decline in $\mathrm{FEV}_{1}$ was smaller among the regular users.

We found a significant association between the acute and chronic effects of exposure to welding fume. Decline in $\mathrm{FEV}_{1}$ across the shift was a significant predictor of annual decline in $\mathrm{FEV}_{1}$. To our knowledge, none of the previous studies on welders have considered this question. However, studies among cotton ${ }^{20}$ and grain workers ${ }^{21} 22$ have found that acute responses to occupational exposure, measured as changes in $\mathrm{FEV}_{1}$ across the shift, are a significant determinant of annual change in $\mathrm{FEV}_{1}$. Furthermore, it is biologically plausible that recurrent acute obstructive changes lead to chronic airways obstruction. ${ }^{23}$

The main limitations of our study are that the number of workers was small, especially in subgroup analysis, and that the follow up period, 2 years, was short for assessing the effect of exposure to welding on pulmonary function changes. Nevertheless, even in that short period there was a significant difference in annual decline in $\mathrm{FEV}_{1}$ between welders and non-welders who smoked.

As our study was longitudinal all workers could serve as their own controls and we avoided in part some of the typical problems in cross sectional studies including the healthy worker effect. We also attempted to study workers who had left their workplace or who had retired to reduce the healthy worker effect. However, only 11 were surveyed at home or in a new workplace and 41 workers could not be studied, mostly because they had changed work and could not be found. Thus, there was still some dropout from the study population and our findings may therefore still have been affected by the healthy worker effect to some extent.

In our study non-smoking non-welders had an unexpectedly steep decline in FVC and $\mathrm{FEV}_{1}$, steeper than that in smoking non- welders or non-smoking welders. The reasons for these inconsistent findings are unclear, and it was not explained by the number of asthmatic subjects in that group, nor by the presence of some ex-smokers and ex-welders in that group; however, the most likely explanation is that it was a chance finding due to the small numbers of workers in this subgroup analysis.

We grouped non-welders and ex-welders together because the ex-welders had stopped welding before study 1 and it was assumed that the effect of welding fumes on decline in lung function does not continue after the end of exposure. There were also some non-welders who had done minimal welding. A similar classification was used for smoking: workers who were ex-smokers during the study 1 were classified as non-smokers because the decline in $\mathrm{FEV}_{1}$ among smokers has been shown to normalise to the same level with never smokers after the end of smoking. ${ }^{24}$ However, if pulmonary function variables continue to decline after exposure to tobacco or after the end of welding, or if they decline just due to occasional, minimal welding, then our method of categorisation would lead to an underestimation of the true difference between welders and non-welders (and between smokers and non-smokers) and could not account for the differences that we have found.

In conclusion, despite the short follow up period and the few workers in our study, smoking welders and welders welding without local exhaust ventilation or respiratory protection had significantly increased risks for accelerated decline in $\mathrm{FEV}_{1}$. Even though no significant difference was noted among non-smokers, it should be stressed that effective preventive measures should be available for all welders. The use of masks and negative pressure respirators has been found to be unfeasible because of heat, moisture and discomfort. ${ }^{2526}$ Thus, local exhaust ventilation is the most practical method to avoid exposure to welding fumes, and is highly recommended, as is stopping smoking.

The Wellington Asthma Research Group is funded by a Programme Grant and this study was funded in part from a Programme Grant and this study was funded in part from a New Zealand. RE-P also received support from the Yrjö Jahnsson foundation, The Finnish Anti-Tuberculosis Association son foundation, The Finnish Anti-Tuberculosis Association
Foundation, and Finnish Cultural Foundation. We thank Hazel Foundation, and Finnish Cultural Foundation. We thank Hazel Armstrong of the Engineering, Printing, and Manufacturing
Union, and the management, union delegates, and workers who Union, and the management, union dele
participated, or assisted with this study.

1 Sferlazza SJ, Beckett WS. The respiratory health of welders. Sterlazza SJ, Beckett WS. The respiratory health of weld
State of the art. Am Rev Respir Dis 1991;143:1134-48.

2 Moulin J. A meta-analysis of epidemiologic studies on lung cancer in welders. Scand $\mathcal{f}$ Work Environ Health 1997;23: cancer in

3 Francis T. A study of immediate effects of welding fume on pulmonary function. $\mathcal{F} R$ Nav Med Serv 1982;68:136-44.

4 Keimig DG, Pomrehn PR, Burmeister LF. Respiratory symptoms and pulmonary function in welders of mild steel: a cross-sectional study. Am f Ind Med 1983;4:489-99.

5 Akbarkhanzadeh F. Short-term respiratory function changes in relation to workshift welding fume exposures. Int Arch Occup Environ Health 1993;64:393-7.

6 Kilburn KH, Warshaw RH, Boylen CT, et al. Respiratory symptoms and functional impairment from acute (crossshift) exposure to welding gases and fumes. Am ₹ Med Sci 1989;298:341-9.

7 Akesson B, Skerfving S. Exposure in welding of high nickel alloy. Int Arch Occup Environ Health 1985;56:111-7.

8 Hunnicutt TN, Cracovaner DJ, Myles JT. Spirometric

Hunnicutt TN, Cracovaner DJ, Myles JT. Spirometric
measurements in welders. Arch Environ Health 1964;8: measur 
9 McMillan GHG, Plethybridge RJ. A clinical radiological and pulmonary function case-control study of 135 dockyard welders aged 45 years and over. 7 Soc Occup Med 1984;34:3-23.

10 Cotes JE, Feinman EL, Male VJ, et al. Respiratory symptoms and impairment in shipyard welders and caulker burners. Br F Ind Med 1989;46:292-301.

11 Chinn DJ, Stevenson IC, Cotes JE. Longitudinal respiratory survey of shipyard workers: effects of trade and atopic status. Br F Ind Med 1990;47:83-90.

12 Chinn DJ, Cotes JE, El Gamal FM, et al. Respiratory health of young shipyard welders and other tradesman studied cross sectionally and longitudinally. Occup Environ Med 1995;52:33-42.

13 Beckett WS, Pace PE, Sferlazza SJ, et al. Airway reactivity in welders: a controlled prospective cohort study. $\mathcal{F}$ Occup Environ Med 1996;12:1229-38.

14 Fishwick D, Bradshaw L, Slater T, et al. Respiratory symptoms, across-shift lung function changes and lifetime exposures of welders in New Zealand. Scand 7 Work Environ Health 1997;23:351-8.

15 Burney P, Luczynska C, Chinn S, et al. The European Community Respiratory Health Survey. Eur Respir $\mathcal{F} 1994$; 7:954-60.

16 Quanjer $\mathrm{PhH}$, ed. Standardization of lung function tests - 1993 update. Report working party for the European Community for Steel and Coal. Eur Respir $\mathcal{f}$ 1993;6(suppl): 16

17 SAS language guide for personal computers. Carey, NC: SAS Institute, 1988
18 Özdemir Ö, Numanoglu N, Gönüllü U, et al. Chronic effects of welding exposure on pulmonary function tests and respiratory symptoms. Occup Environ Med 1995;52: $800-3$

19 Becklake MR. Chronic airflow limitation: its relationship to work in dusty occupations. Chest 1985;88:608-17.

20 Glindmeyer HW, Lefante JJ, Jones RN, et al. Cotton dust and across-shift change in $\mathrm{FEV}_{1}$ as predictors of annual change in FEV. Am f Respir Crit Care Med 1994;149.58490.

21 Enarson DA, Vedal S, Chan-Yeung M. Rapid decline in $\mathrm{FEV}_{1}$ in grain handlers. Am Rev Respir Dis 1985;132:81417

22 Tabona M, Chan-Yeung M, Enarson D, et al. Host factors affecting longitudinal decline in lung spirometry among grain elevator workers. Chest 1984;85:782-6.

23 Becklake MR. Relationship of acute obstructive airway change to chronic (fixed) obstruction. Thorax 1995; 50(suppl 1):516-21.

24 Kerstjens HAM, Rijcken B, Schouten JP, et al. Decline of $\mathrm{FEV}_{1}$ by age and smoking status: facts, figures, and fallacies. Thorax 1997;52:820-7.

25 Beckett WS. Welding. In: Harber P, Schenker MB, Balmes $\mathrm{JR}$, eds. Occupational and environmental respiratory disease. St Louis: Mosby, 1996.

26 Nielsen R, Gwodsdow AR, Berglund LG, et al. The effect of temperature and humidity levels in a protective mask on user acceptability during exercise. Am Ind Hyg Assoc f 1987;48:639-45. 